\title{
Field Dependence-Independence in Second-Language Acquisition: Some Forgotten Aspects
}

\author{
Carolina Tinajero* and Fernanda Páramo \\ University of Santiago de Compostela
}

\begin{abstract}
This study examined the role of sex and intelligence in the relationship between field dependence-independence and second language acquisition for a sample of 383 students (187 gitls and 196 boys) aged between 13 and 16. The Portable Rod and Frame Test (PRFT) and the Embedded Figures Test (EFT) were used to evaluate cognitive style. A two-way covariance analysis, with intelligence as the covariate, was employed to investigate differences in second language achievement between students classified as either fielddependent or field-independent. A cluster analysis using z scores was examined to study the performance of subjects classified as either field-dependent or field-independent according to scores obtained on the EFT and the PRFT ("coincident" subjects) and those classified as field-dependent in one test and field-independent in the other ("non-coincident" subjects). No statistically significant differences between the two groups were obtained when cognitive style was defined by scores on the PRFT. When field dependenceindependence was measured by scores on the EFT, field-independent girls performed better than field-dependent girls ( $\mathrm{p}<.005$ ), but this outcome was not observed for boys. These results suggest a differential contribution of the "perceptive" and "cognitive" components of field dependence-independence and a modulating role by sex.

Key words: cognitive style, field dependence-independence, second-language acquisition
\end{abstract}

En el presente estudio se examina el papel del sexo y de la inteligencia en la relación de la dependencia-independencia de campo con la adquisición de una segunda lengua en una muestra de 383 chicos y chicas de entre 13 y 16 años. Se utilizó el Portable Rod and Frame Test (PRFT) y el Embedded Figures Test (EFT) para evaluar el estilo cognitivo. Se aplicó un analisis de covarianza de doble vía, con la inteligencia como covariable, con el objetivo de comparar el rendimiento de dependientes e independientes de campo. Además, se realizó un análisis de conglomerados con las puntuaciones típicas para explorar el rendimiento de los sujetos clasificados como dependientes o independientes de campo según el EFT y el PRFT ("coincidentes") y aquéllos clasificados como dependientes de campo en una prueba e independientes de campo en la otra ("no coincidentes"). No se obtuvieron diferencias estadísticamente significativas en rendimiento según las puntuaciones en el PRFT. Clasificados los sujetos según el EFT, las chicas independientes de campo rendían mejor que las dependientes de campo $(p<.005)$, lo que no ocurria entre los chicos. Estos resultados sugieren una contribución diferencial de los componentes "perceptivo" y "cognitivo" de la dependencia-independencia de campo y un efecto modulador del sexo. Palabras clave: estilo cognitivo, dependencia-independencia de campo, adquisición de una segunda lengua

This research was supported by a grant from the Xunta de Galicia, XUGA 21106A91

* Correspondence concerning this article should be addressed to Dr. Carolina Tinajero, Departamento de Psicología Evolutiva y de la Educación. Facultad de Psicología. Universidad de Santiago de Compostela. Campus Universitario Sur. 15706 - Santiago de Compostela (Spain). E-mail: pecativa@usc.es 
Field dependence-independence (FDI) is defined as a cognitive style that refers to individual differences with regard to the preference of internal versus external cues in the organization of behavior (Witkin \& Goodenough, 1981). Confidence placed in internal cues, which is characteristic of field-independent subjects, is associated with a greater restructuring ability; that is, an increased facility to impose personal organization on information obtained or derived from the environment. Field-dependent subjects, who are more sensitive to external cues, tend to accept percepts or symbolic representations as they are given. These tendencies appear to have a different adaptative value in an educational environment. Field-independent subjects consistently achieve higher academic levels than field-dependent subjects, whether specific subjects or global performance are considered (Davis, 1991; Tinajero \& Páramo, 1990, 1997). However, a growing body of research which examines second-language learning in relationship to cognitive style suggests that second language learning may be enhanced by behavioral characteristics associated with both poles of style-dimension. On the one hand, greater restructuring ability of fieldindependent subjects may favor the learning and application of linguistic rules (Abraham, 1983), management of different grammatical systems (Alptekin \& Atakan, 1990; Chapelle \& Robetts, 1986), and the successful execution of common classroom exercises such as Cloze Tests (Chapelle \& Roberts; Hansen, \& Stanfield, 1981). Chapelle and Green (1992) are more precise, having established correspondence between the student's ability to disembed and his/her linguistic analysis skills, i.e. the ability to recognize the grammatical functions of words in phrases, and to infer grammatical rules based on the language input. On the other hand, Brown (1987) has suggested that interpersonal skills of field-dependent subjects may demonstrate greater gains in second-language acquisition when they have structured contact with native speakers.

Such diversity of theoretical interpretations, however, does not correspond to the methodological approaches employed in studies aimed at examining the influence of cognitive style on second language learning. The preceding studies have only examined the relationship between the performance on perceptive disembedding tests, such as the Embedded Figures Test (EFT; see Witkin, Oltman, Raskin, \& Karp, 1971), used to evaluate FDI, and academic tasks such as conversation, reading, dictation, or standardized tests such as the Test of English as a Foreign Language (TOEFL; Educational Testing Service, 1983). Even using samples of foreign language students in their home countries (Abraham \& Chapelle, 1992; Alptekin \& Atakan, 1990; Carter, 1988; Chapelle, 1988; Hansen, 1984; Hansen \& Stanfield, 1981), or pupils in courses taught in a country where the language being studied is also spoken (Abraham, 1983, 1985; Chapelle \& Roberts, 1986; Jamjeson, 1992; Jamieson \& Chapelle, 1987), field-independent subjects persistently have shown higher achievement levels than have field-dependent subjects.
To use a single test to evaluate FDI implies that the researcher ignores the bidimensional nature of the construct. At one stage, Witkin and co-workers considered that tests of perception of the upright, such as the Rod and Frame Test (RFT; Witkin \& Asch, 1948a, 1948b), and perceptual disembedding tests, such as the EFT, measured the same thing. However, the results of correlational, factor-analytic, and experimental studies of subjects' scores convinced these workers of the need to make a distinction between classifications of field dependence or independence in subjects' performance on each test. It was hypothesized that a subject's performance on tests of vertical perception might, in fact, be governed by that subject's position on a bipolar dimension of confidence in vestibular versus visual cues, and that this dimension was distinct from (though clearly related to) the unipolar dimension of restructuring ability (Witkin \& Goodenough, 1981). Subsequent studies have confirmed the bidimensionality of field dependenceindependence (Brenet, Ohlmann, \& Marendaz, 1988; Goodenough, 1981; Goodenough, Cox, Sigma, \& Strawderman, 1985; Goodenough, Oltman, \& Cox, 1987; Noel \& Baligand, 1984; Ohlmann, 1990).

In the opinion of Witkin and his co-workers, the bipolar dimension of confidence in vestibular versus visual cues reflects the degree to which a person's actions are autonomous with respect to his/her environment; this dimension is thus directly linked to affective-motivational aspects of personality, as revealed in interpersonal relations. In fact, as the authors themselves included in successive revisions (Witkin \& Goodenough, 1977, 1981; Witkin, Goodenough, \& Oltman, 1979), subjects who behave more autonomously with regard to the external visual field in vertical perception are also more autonomous in their interpersonal relationships: they are characterized by others as being people with initiative and self-confidence, with clearer boundaries between themselves and other objects, and being less sensitive to social cues.

Similarly, the restructuring-ability dimension appears to be more closely related to cognitive abilities. Its involvement in numerous intellectual tasks, such as concept acquisition and problem solving, among others, has been widely reported (Witkin \& Goodenough, 1981). Consequently, it would seem relevant to use both tests of vertical perception and perceptual disembedding together to examine the influence, if any, of the components of FDI or to analyze the performance of subjects with coincident or non-coincident positions in both tests. With reference to the latter, Ohlmann (1983) added two new groups to the normal classification of subjects as either field-dependent or field-independent, which he calls analytical and postural. The analytical classification includes those subjects with high scores in perceptive disembedding and low scores in vertical perception, and the postural classification identifies subjects who have low scores in perceptive disembedding and high scores in vertical perception.

Another essential aspect that has been ignored in past research efforts is the possible influence of other variables 
on the observed relationship between cognitive style and language learning. For example, the prevalence of field dependence differs between girls and boys; girls, on average, exhibiting greater field dependence than boys (Cairns, Malone, Johnston, \& Cammock, 1985; Witkin, 1979). Intelligence as a variable is of particular interest, since the superior performance of field-independent subjects in certain intellectual tasks has led some authors to suggest that cognitive style is nothing more than an alternative way of looking at dimensions of ability. In fact, numerous studies have reported a correlation between measures of FDI and various types of ability; specifically general intelligence and spatial aptitudes (Bloom-Feshbach, 1980; Laosa, 1980; McKenna, 1983, 1984; McKenna, Duncan, \& Brown, 1986; Witkin, Dyk, Faterson, Goodenough, \& Karp, 1962). However, some authors have considered FDI to be completely separate from intelligence, and invoke basic arguments which go beyond the empirical question of relationships between measures. For example, it has been argued that "ability" deseribes performance in a given task whereas "style" describes the way the task is approached (Brodzinsky, 1985; Globerson, 1983, 1989; Kogan, 1971; Messick, 1994). Regardless of one's personal opinion of the strength of the various arguments relating style and ability, it seems increasingly clear that consideration of the possibility of overlap between these two variables is essential in any study of field dependence-independence and intellectual variables.

The overlap of FDI with intelligence has been a point of discussion in some of the studies dealing with the relationship between cognitive style and second language acquisition (Chapelle, 1988; Chapelle \& Green, 1992), although only D'Anglejan and Renaud (1985) provided empirical support for the contribution of cognitive style to linguistic achievement, once intelligence had been controlled (in that study, intelligence was evaluated using Raven's Progressive Matrices; Raven, 1962). The authors examined the predictive value of field dependence-independence, intelligence, and other variables with regard to the acquisition of French by 391 immigrants in Canada ranging from 17 to 63 years of age, through a multiple regression analysis. They also carried out an analysis of variance comparing language acquisition of students who had been classified as either "good" or "poor" students based upon teacher evaluations of their overall academic performance in school. Although this second analysis brought to light significant inter-group differences for cognitive style, FDI scores did not make a significant contribution to learning French.

Witkin and Berry (1975) and Pande and Kothari (1969) pointed out that the requirements of the Raven's are similar to those present in the embedided figures tests: in fact, perceplual analysis is required to obtain solutions for the Raven's Matrices items; and, one of its subtests even calls for perceptual disembedding. Our knowledge of the nature of intelligence and cognitive style is incomplete as long as researchers continue to disregard the importance of the convergence of these two constructs.

The purpose of this study was to examine the relationship between field dependence-independence (as measured by the EFT (cognitive) and the RFT [perceptive]) and the acquisition of English by Spanish-speaking children while controlling for intelligence. The study assesses the role that sex plays in this relationship and evaluates whether it appears in both parts of FDI (perceptive and cognitive), as revealed by its different measures. The role of the affectivemotivational component of cognitive style, as measured by RFT, in second language leaming may be different from the cognitive component as assessed by EFT. If the interpersonal abilities of ficld-dependent subjects enhances performance in this area, then subjects with low RFT scores may achieve higher grades in English than subjects with high scores.

\section{Method}

\section{Subjects}

Participants in this study were 383 13- to 16-year-olds ( 187 girls and 196 boys) living in Santiago de Compostela, Spain, where they were enrolled in Secondary Grade 1 (Grade 9 in USA) in three high-schools.

As the focus of this investigation was upon a dimension that establishes a continuum between two possible extreme positions, we agreed with Messick (1994) that intermediate scores do not appropriately define characteristics of fieldindependent and field-dependent subjects. For this reason, we identifjed subjects with extreme FDI scores, which led to a final sample of 93 girls ( 45 field-independent and 45 field-dependent) and 96 boys (49 field-independent and 47 field-dependent). (See subsection "Procedures" for details on how the final sample was obtained.)

\section{Measures}

Evaluation of field dependence-independence. Cognitive style was evaluated using the Embedded Figures Test - EFT, the Group Embedded Figures Test - GEFT (Witkin et al., 1971), and the Portable Rod and Frame Test - PRFT (Oltman, 1968). The EFT consists of 24 complex colored figures and 8 simple geometric figures. Each complex drawing is shown to the subject together with the corresponding simple figure, which is then withdrawn; the subject must then locate the simple figure within the complex one. The final score is the time taken to complete the task correctly for all 24 drawings, the more field-independent subjects being identified as those who finish the fastest. GEFT is a variant of the EFT produced for group administration in a booklet form with 25 complex shaded figures. The simple figures appear on the back of the last page, thus preventing the subject from seeing these 
figures simultaneously with the complex ones; each simple figure is accompanied by a letter to help in its identification. The task is the same as in the EFT, although there is a timelimit to completion of each section of the GEFT. The final score is the total number of simple figures that are correctly located.

The PRFT consists of a rectangular enclosure of translucent plastic. The subject is seated at one end with his/her head fixed to a support. The sides of the enclosure form a frame for the opposite end; a rod is placed in its center. Both frame and rod can be tilted to the left or right. Once the frame has been inclined $28^{\circ}$ to the left or to the right, the subject must place the rod in a vertical position, overcoming an incorrect visual referent given by the frame. The subject's score is the total number of the absolute deviations in degrees of the rod from the vertical in eight trials. It is thought that field-dependent subjects tend to use their external visual field as a principal referent to locate the upright, which leads to larger deviations when they place the rod; while field-independent subjects rely primarily on their own vestibular, tactile, and kinesthetic senses and more easily find the upright, resulting in smaller deviations.

Evaluation of intelligence. Intelligence was evaluated using Cattell's Culture Fair Intelligence Test (Cattell \& Cattell, 1973). The test has four timed sets of problems (series completion, odd-one-out, matrices, and topology) each using geometric symbols as stimulus materials. The final score is the total number of correct answers attained in the four subtests.

Evaluation of second-language acquisition. English achievement was measured by the mean grades obtained at school in the previous academic year (primary Grade 8). At this level, English language teaching deals with phonemics, lexical, and, particularly, grammatical structures.

\section{Procedure and Data Analysis}

Group tests (e.g., GEFT and Cattell's Culture Fair Test) were administered by the authors in each classroom. After identifying those subjects who obtained extreme scores on the GEFT (their scores fell in the lowest and highest quartiles of the distribution), PRFT and EFT were administered to them individually. Field-dependent and field-independent subjects were defined as those who scored respectively above or below the median of the distributions of each test separately.

A two-way (EFT $x$ PRFT) covariance analysis, with intelligence scores as the covariate, was applied to assess whether there were statistically significant differences between field-dependent and field-independent subjects in English achievement after controlling for intelligence. Effects of spatial aptitudes associated with cognitive style were also considered to be ruled out, as such aptitudes are reported to be measured by Cattell's test and other g-factor tests (Snow \& Lohman, 1989; Vernon, 1972). A cluster analysis with $z$ scores was also run in order to study the performance of coincident and non-coincident subjects. Coincident subjects are defined as those whose classification as fielddependent or field-independent was consistent with scores on both the EFT and the PRFT. Non-coincident subjects are those who were classified as field-dependent in one test and field-independent in the other. The analyses were carried out separately for boys and girls. The separate treatment of the two FDI measurements in the ANCOVA is thus complemented by their joint treatment in the cluster analysis. The first approximation provided information about the contribution of the components of FDI (cognitive and perceptive) to academic performance, whereas the second analysis provided information about the behavior of subjects with different positions with regard to these components.

\section{Results}

Table 1 shows the means and standard deviations in English grades for field dependent and independent boys and girls as classified by the EFT or the PRFT. Fieldindependent children of both sexes obtained higher grades in English than field-dependent children, as shown in Table 1 , but this difference was statistically significant only for girls when classified by their EFT scores, $F(1,93)=7.8, p$ $<.005,1-\beta=0.77$.

Table 1

Means and Standard Deviations in English Grades for Field Dependent and Field Independent Boys and Girls, classified by their Scores on the EFT (upper rows) and on the PRFT (lower rows)

\begin{tabular}{|c|c|c|c|c|c|c|}
\hline & \multicolumn{3}{|c|}{ Field Independent Subjects } & \multicolumn{3}{|c|}{ Field Dependent Subjects } \\
\hline & $N$ & $M$ & $S D$ & $N$ & $M$ & $S D$ \\
\hline Girls & 48 & 2.32 & 1.23 & 45 & 1.33 & .98 \\
\hline Boys & 47 & 1.47 & .97 & 47 & 1.12 & .86 \\
\hline Girls & 48 & 2.06 & 1.23 & 45 & 1.58 & 1.06 \\
\hline Boys & 49 & 1.37 & 81 & 47 & 1,21 & .86 \\
\hline
\end{tabular}


Table 2 Cluster Centers for Boys' and Girls'Scores on the EFT, PRFT, Cattell's Culture Fair Test, and English Achievement

\begin{tabular}{|c|c|c|c|c|c|}
\hline & CLUSTER & EFT & PRFT & INTELLIGENCE & ENGLISH \\
\hline \multirow[t]{4}{*}{ GIRLS } & 1 & 1.1417 & 1.9777 & -.8715 & .0745 \\
\hline & 2 & -.4034 & -.4418 & .1948 & -.1627 \\
\hline & 3 & -.7318 & -.4033 & .8530 & 2.0720 \\
\hline & 4 & 1.4492 & -.0785 & -1.0765 & -.5401 \\
\hline \multirow[t]{4}{*}{ BOYS } & 1 & -.0832 & 6863 & -.0322 & 1.2809 \\
\hline & 2 & 1.3667 & 1.6869 & -.9219 & -.3352 \\
\hline & 3 & -.7212 & -.5404 & 1.0804 & -.1590 \\
\hline & 4 & .0882 & -.4292 & -.5767 & -.7209 \\
\hline
\end{tabular}

The cluster analysis brought to light new differential sex results. As may be seen in Table 2, where the cluster centers obtained in the analysis are shown, four profiles are distinguished for boys, coinciding with the types established by Ohlmann (1983): field-dependent, field-independent, analytical, and postural. The highest level of achievement is obtained by analytical subjects and the lowest level by postural subjects, with field-dependent and field-independent boys occupying the intermediary positions. The analytical profile does not appear in girls. However, two fieldindependent groups of girls are obtained, both with high achievement. Consistent with the findings for boys, the postural girls have the lowest level of achievement.

\section{Discussion}

The results of this investigation extend the view offered by the preceding studies about the relationship between FDI and second-language acquisition. We have considered the perceptual and cognitive components of field dependenceindependence. We tested to see whether there was any significant difference between subjects of both sexes with extreme scores on the EFT and the PRFT, after removing the variability attributable to intelligence and/or spatial aptitudes.

When scores from the EFT are considered to identify field-dependent and field-independent subjects, inconsistent results are obtained for boys and girls. Although fieldindependent girls show higher achievement levels than fielddependent ones, the difference between field-dependent and field-independent boys is nonsignificant. These differential findings might suggest the intervention of factors associated with sex or perhaps sex roles. As shown by the results of Balistreri and Busch-Rossnagel (1989), Chynn, Garrod, Demick and De Vos (1991), Hulfish (1978), and Van Blerkom (1988), sex roles from differing perspectives, such as those associated with sex role self-perception and perceived adequacy of tasks in the sex role, may influence the way in which modes of functioning that are typical of cognitive styles appear. Perhaps the goal of mastering a second language may be seen by students in Spain as being more in agreement with the male role, because of the higher status which men's jobs tend to have. This circumstance might cause a greater involvement of boys in secondlanguage learning, compensating for the difficulties which field-dependent boys would encounter because of their cognitive style.

These interpretations do not contradict the imporance of restructuring aptitude for second-language acquisition. As shown by the cluster analysis, the subjects with the higher performance levels were those who obtained the lowest scores on the EFT (less time means more restructuring aptitude). Nevertheless, a major effort would be necessary to investigate the real implication of disembedding abilities and of restructuring in academic achievement. Some ideas may be extracted for future investigations from studies on the relationship between FDl and information processing. For example, attentional differences have been observed among subjects with different cognitive styles and may underlie disembedding skills and restructuring abilities (Clark \& Roof, 1988; Marendaz, 1985). Considering the implications for these observed differences in level of task performance as they relate to second-language learning would help to clarify which aspects of language acquisition present the greatest difficulties for extreme field-dependent subjects. The intention could be to seek ways to modify their behavior or compensate for it by revising both teaching strategies and instructional materials to support this type of learning.

The ANCOVA results indicate that the PRFT scores do not imply significant differences in the ability to learn English. However, the cluster analysis reveals that subjects with good performance in the PRFT have the lowest levels of achievement. Particularly interesting is the fact that boys with a cognitive-analytical orientation, while not scoring highest on the EFT or even being more intelligent, achieve the strongest academic performance. It would appear that their performance is favored by the fact that they are fielddependent in the PRFT. Some of the characteristics of an affective-motivational nature related to the perceptive 
component of the FDI probably play a modulating role in second-language learning. One might speculate that this would be more clearly revealed in educational surroundings with eminently interactive instructional methodologies, in which, as Brown (1987) suggested, the interpersonal skills of the field-dependent subjects would have an enhancing effect. This possibility should be explored in future studies.

\section{References}

Abraham, R. (1983). Relationship between use of the strategy of monitoring and cognitive style. Studies in Second-language acquisition, 6, 17-32.

Abraham, R. (1985). Field independence-dependence and the teaching of grammar. TESOL Quarterly, 20, 689-702

Abraham, R., \& Chapelle, C.A. (1992). The meaning of Cloze test scores: An item difficulty perspective. Modern Language Joumal, 76, 468-479.

Alptekin, C., \& Atakan, S. (1990). Field dependence-independence and hemisphericity as variables in $\mathrm{L} 2$ achievement. Second Language Research, 6, 135-149.

Balistreri, E., \& Busch-Rossnagel, N.A. (1989). Field independence as function of sex, sex-roles, and the sex-role appropriateness of the task. Perceptual and Motor Skills, 68, 115-121.

Bloom-Feshbach, J. (1980). Differentiation: Field dependence, spatial ability, and hemispheric specialization. Journal of Personality. 48, 135-148.

Brenet, F., Ohlmann, T., \& Marendaz, C. (1988). Interaction vision/posture lors de la localisation d'une cible enchasée. Bulletin de Psychologie, 388, 22-30.

Brodzinsky, D.M. (1985). On the relationship between cognitive styles and cognitive structures, In E.D. Neimark, R. De Lisi, \& J.L. Newman (Eds.), Moderators of competence (pp. 147174). Hillsdale, NJ: Erlbaum.

Brown, H.D. (1987), Principles of language learning and teaching. Englewood Cliffs, NJ: Prentice Hall.

Cairns, E., Malone, S., Johnston, J., \& Cammock, T. (1985). Sex differences in children's group embedded figures test pertormance. Personality and Individual Differences, 6, 653-654.

Carter, E.F. (1988). The relationship of field-dependent/independent cognitive style to Spanish language achievement and proficiency: A preliminary report. Modern Language Journal, $72,21-30$.

Cattell, R.B., \& Cattell, A.K.S. (1973). Measuring Intelligence with The Culture Fair Test. Champaign, IL: Institute for Personality and Ability Testing.

Chapelle, C. (1988). Field independence: A source of language test variance? Language Testing, 5, 62-82.

Chapelle, C., \& Green, P. (1992). Field independence/dependence in second-language acquisition research. Language-Learning, $42,47-83$.

Chapelle, C., \& Roberts, C. (1986). Ambiguity tolerance and field independence as predictors of proficiency in English as second language. Language Learning, 36, 27-45.
Chynn, W.W., Garrod, A., Demick, J., \& DeVos, E, (1991). Correlations among field dependence-independence, sex, sexrole stereotype, and age of pre-schoolers. Perceptual and Motor Skills, 73, 747-756.

Clark, H.T., \& Roof, K.D. (1988). Field dependence and strategy use. Perceptual and Motor Skills, 66, 303-307.

D'Anglejan, A., \& Renaud, C. (1985). Learner characteristics and second-language acquisition: A multivariate study of adult immigrants and some thoughts on methodology. Language Learning, 35, 1-19.

Davis, J.K. (1991). Educational implications of field dependenceindependence. In S. Wapner, \& J. Demick (Eds.), Field dependence-independence: Cognitive style across the life span. Hillsdale, NJ: Lawrence Erlbaum Associates.

Educational Testing Service. (1983). TOEFL Test and score manual. Princeton, NJ: ETS.

Globerson, T. (1983). Mental capacity, mental effort, and cognitive style. Developmental Review, 3, 292-302.

Globerson, T. (1989). What is the relationship between cognitive style and cognitive development? In T. Globerson \& T. Zelniker (Eds.), Cognitive style and cognitive development (pp. 71-85). Norwood: Ablex.

Goodenough, D.R. (1981). An entry in the great frame-tilt judging contest. Perceptual and Motor Skills, 52, 43-46.

Goodenough, D.R., Cox, P.W., Sigma, E., \& Strawderman, W.E. (1985). A cognitive-style conception of the field-dependence dimension. Cahiers de Psychologie Cognitive, 5, 687-706.

Goodenough, D.R., Oltman, P.K., \& Cox, W. (1987). The nature of individual differences in field dependence. Journal of Rexearch in Personality, 21, 81-99.

Hansen, L. (1984). Field dependence-independence and language testing: Evidence from six Pacific island' cultures. TESOL Quarterly, 18, 311-324.

Hansen, J., \& Stanfield, C. (1981). The relationship of fielddependent-independent cognitive style to foreign language learning achievement. Language Learning, 31, 349-367.

Hulfish, S. (1978). Relationship of role identification, self-esteem, and intelligence to sex differences in field independence. Perceptual and Motor Skills, 47, 835-842.

Jamieson, J. (1992). The cognitive styles of reflection impulsivity and field independence dependence and ESL success. Modern Language Joumal, 76, 491-501.

Jamieson, J., \& Chapelle, C. (1987). Working styles on computers as evidence of second language learning strategies. Language Leaming, 37, 523-544.

Kogan, N. (1971). Las implicaciones de los estilos cognitivos en la educación. In G.S. Lesser (Ed.), La psicología en la práctica educativa (pp. 303-366). México: Trillas.

Laosa, L.M. (1980). Maternal teaching strategies and cognitive styles in Chicano families. Journal of Educational Psychology, $72,45-54$.

Marendaz, C. (1985). Global precedence and field dependence: Visual routines? Cahiers de Psychologie Cognitive, 5, 727-745.

McKenna, F.P. (1983). Field dependence and personality: A reexamination. Social Behavior and Personality, 11, 51-55. 
McKenna, F.P. (1984). Measures of field dependence: Cognitive style or cognitive ability. Journal of Personality and Social Psychology, 47, 593-603.

McKenna, F.P., Duncan, J., \& Brown, D. (1986). Cognitive abilities and safety on the road: A re-examination of individual differences in dichotic listening and search for embedded figures. Ergonomics, 29, 649-663.

Messick, S. (1994). The matter of style: Manifestations of personality in cognition, learning, and teaching. Educational Psychologist, 29, 121-136.

Noel, B., \& Baligand, F. (1984). Analyse des resultats aux items du G.E.F.T. Scientia Paedagogica Experimentalis, 21, 225-236.

Ohlmann, T. (1983). Dépendance-indépendance du champ et conduites cognitives. Grenob]e: Laboratoire de Psychologie Experimentale.

Ohlmann, T. (1990). La perception de la verticale lors de conflicts vision/posture. Un exemple de processus vicariants. In M. Reuchlin, D. Longeot, C. Marendaz, \& T. Ohlmann (Eds.), Conaître différemment (pp. 33-66). Nancy, France: Presses Universitaires.

Oltman, P.K. (1968). A portable rod and frame apparatus. Perceptual and Motor Skills, 26, 503-506.

Pande, C.G., \& Kothari, S. (1969). Field dependence and the Raven's progressive matrices. Psychologia, 12, 49-51.

Raven, J. (1962). Colored progressive matrices. New York: Psychological Corp.

Snow, R.E., \& Lohman, D.F. (1989). Implications of cognitive psychology for educational measurement. In R.L. Linn (Ed.), Educational measurement (3rd ed., pp. 263-331) New York: MacMillan Publishing Co.

Tinajero, C., \& Páramo, M.F. (1990). Fjeld dependence-independence and performace in school: An argument against neutrality of cognitive sytle. Perceptual and Motor Skills, 70, 1079-1087.

Tinajero, C., \& Páramo, M.F. (1997). Field dependence-independence and academic achievement: $A$ re-examination of their relationship. British Journal of Educational Psychology, 67, 199-2/2.
Van Blerkom, M.L. (1988). Field dependence, sex role, selfperceptions, and mathematics achievement in college students: A closer examination. Conremporary Educational Psychology, 13, 339-347.

Vernon, $P$. (1972). The distinctiveness of field independence. Joumal of Personality, 40, 366-391.

Witkin, H.A. (1979). Socialization, culture, and ecology in the development of group and sex differences in cognitive style. Human Development, 22, 358-372.

Witkin, H.A., \& Asch, S.E. (1948a). Studies in space orientation. III. Perception of the upright in the absence of visual field. Joumal of Experimental Psychology, 38, 603-614.

Witkin, H.A., \& Asch, S.E. (1948b). Studjes in space orientation. IV. Further experiments on perception of the upright with displaced visual frelds. Journal of Experimental Psychology, $38,762-782$.

Witkin, H.A., \& Berry, J.W. (1975). Psychological differentiation in cross cultural perspective. Journal of Cross-Cultural Psychology; 6, 4-87.

Witkin, H.A., Dyk, R.B., Faterson, H.F., Goodenough, D.R., \& Karp, S.A. (1962). Psychological differentiation. New York: Wiley

Witkin, H.A., \& Goodenough, D.R. (1977). Field dependence revised. Princeton, N.J.: Reseatch Bulletin E.T.S.

Witkin, H.A., \& Goodenough, D.R. (1981). Cognitive styles: Essence and origin. New York: Wiley.

Witkin, H.A. Goodenough. D.R., \& Oltman, P.K. (1979). Psychological differentiation: Current Status. Journal of Personality and Social Psyhology, 37, 1127-1145.

Witkin, H.A., Oltman, P.K., Raskin, E., \& Karp, S.A (1971). A manual for the embedded figures tests. Palo Alto, CA: Consulting Psychologist Press.

Received June 6, 1996 Revision received June 30, 1997 Accepted July 14, 1997 